\title{
The Pain: How Does Anthropology Look at it? Suffering of Body and Mind
}

\author{
RAVINDER SINGH \\ Department of Medical Anthropology \\ University of Delhi, Delhi, India \\ medicalanthropology.ihbas@gmail.com
}

\begin{abstract}
This paper reviews pain, social and physical, and its suffering in and beyond the body. It has reviewed evidences for neuro-chemical and neural overlap between social and physical pain. It also explores the consequences of this overlap followed by the sociocultural aspects of pain through an anthropological lens. This is an anthropological exploration of pain for the benefit of the understanding of our clinicians about human pain and suffering beyond the body in their local world.
\end{abstract}

KEY WORDS: Pain, Body and Mind, Culture

\section{Introduction}

Anthropology of Pain...

... various forms of pain from an anthropological point of view. First, I shall try to show the necessity and usefulness of physical pain as a voice of the Freudian "reality principle" that speaks against the excesses and consequences of the opposite "pleasure principle". Then, I shall proceed to various forms of spiritual pain, such as fears and anguish. Even there, pain and worry are not only the necessary background for relief and joy, but can be something like a last resort for escaping from the deep feelings of the void and 
nothingness. In the last step, I shall briefly mention shared pains and sorrows as interpersonal phenomena, which link us with others and contribute to building up relations of compassion, charity and love.

(An excpert of Inaugural Lecture, International Psychoanalytic Association World Congress, July 31, 2013)

Human beings often experience social events that threaten social relationships like divorce and breakups, exclusion from groups, deaths of loved ones, natural disaster etc. Then our body adopts various trajectories of pain and transcribes the descriptions of such experiences as physical pain. Pain, in a cultural context, reveals how people express body pain or social pain as explicit behavior in a community, clinic and wards in a hospital or in society. Pain remains an inseparable part of everyday life, hence the most common and challenging part of clinical practices to manage. The meaning of pain can be different to different people or other ethnic groups. Further, their perception and response may depend upon the cultural as well as personal background varied among people (HELMAN 2007).

In this paper ${ }^{1}$ I review pain in its social and physical dimensions through an anthropological lens. Later, it discusses the neuro-chemical aspects, neural overlap between social and physical pain, and explores some of the consequences of this overlap. This anthropological review will be useful in understanding human pain and suffering beyond the body in their local world of people to our clinicians and other professionals working, particularly, in a tertiary level neuropsychiatry hospital.

This paper is revised after a talk on Pain-Some Cultural Aspects delivered to General Physicians, East Delhi Branch of the Indian Medical Association during celebration of the Brain Awareness Week (BAW), 12-19, March 2014. Institute celebrates BAW every year to mark 12th MarchInternational Brain Day and to create awareness about its diseases and treatment among common people. I wish to express my gratitude to Prof N G Desai, Director and regards to my colleague, now Professor of Neuroanesthesiology, Dr Mukul K Jain, then Chief Coordinator, BAW-2014 who provided this opportunity for interactions with east Delhi physicians. I extend my gratitude to Prof. Ashok Kumar Saxsena, Deptt. of Anesthesiology, GTB Hospital, Dilshad Garden, Delhi for his discussion on pain management clinic in OPD and other physicians who raised various issues and question on pain pleasure, ritualistic pain in cultural practices.

DOI: 10.2478/eas-2018-0006 C University of SS. Cyril and Methodius in Trnava. All rights reserved. 


\section{Pain and Suffering through an Anthropological lens}

Helman (2007) mentioned the neuro-physiological perspective of pain. It may be tissue damage or physiological malfunctioning that arises when a nerve ending is affected. It depends upon two components-the original sensations and the reaction to the sensation, either voluntary or involuntary, which causes pain behavior, expressed through facial expressions, activities, making certain peculiar sounds or words depicting the conditions or appeals for help (FABREGA - TYMA 1976). Often we exhibit involuntary pain behavior. This pain behavior is grouped into two kinds: private and public pain behavior (HELMAN 2007). Private pain behavior denotes behavior in some societies which is hidden and the pain remains unexpressed e.g. Anglo-Saxon adult men and warriors for whom "stiff upper lips" symbolize the ability to bear pain without a cry or without overt behavior. It further indicates the sign of approaching manhood as part of initiation for the rituals marking a transition from boyhood to manhood. Similarly, in another example, the Sun Dance ceremony of the Cheyenne Indians of the Great Plains, young men who wish to display their manhood to gain social prestige through self torture (FABREGA - TYMMA 1976).

In contrast, public pain behavior is the voluntary aspect of the behavior influenced by the cultural, social, and psychological facts determining such pain in public. The interpretation of this pain behavior is explained in two examples, first, American women were asked about their body state and its dysfunctions and only a small number of women reported dysmenorrhea as the dysfunction. Second, abnormal pain which require medical attention and treatment varies culture to culture (ZOLA 1996). This presentation reveals different aspects: how do the people express pain in a clinical or other public setting? Here Zola (1996) illuminates that degree of recognition and gynecological treatment influenced by socio-cultural factors of their lives while the other aspects of public pain may depend upon "Body Image" and the structure and function of the body.

\section{The Pain: Can it be Misfortune?}

Pain may be related to misfortune among simpler societies or folk communities. Anthropologists explore such aspects of human pain in any part of the body which may be linked to a broad spectrum of misfortune. Misfortune is a cultural category, wherein people generally think about everyday events which cause body pain and link such events to misfortune. They question themselves when unexpected events happen - why has it 
happened to me only? Or why has it happened now? What have I done or do I deserve this? Such questions to the self often lead to attributing it to "divine punishment" (HELMAN 2007). Pain as suffering may be related to divine misfortune, witchcraft etc., and the need to follow the ritualistic procedures for its cure in the concerned societies. Such aspects of pain are very common with its treatment procedures or rituals in non-western communities. In contrast, the western treatment of pain either uses pain reliving drugs for psychosomatic pain or psychogenic pain. But clinically they do not consider the social, psychological or moral aspects of pain, which are very common among non-western or simpler communities. In north India, there are various meanings of pain and different metaphors used for expressing pain. Further, these metaphors are treated as "integrated mind-body system of Indian Culture and its treatment through various drugs may depend upon healers or clinicians minimizing the pain" (PUGH 1991).

Pain presentation is culturally determined and depends upon the other factors -their culture values or their emotional expression etc. In contrast there are some cultural groups or families display the presence of the pain in theatrical manner i.e. ItalianAmericans and Irish-American express the pain response as "expressiveness or expansiveness" (ZOLA 1996). Zola (1996) enumerates different aspects of pain presentation among them and warns us as they try to deny or play down the presence of pain. Here, she further mentioned about such behavior as denial as a defense mechanism against the "Oppressive sense of guilt" a common feature among rural Irish people. Further she adds about "self-fulfilling prophecy", among Irish Americans. The non-verbal pain presentations in every culture are also patterned in due course of cultural advancement in the communities. They could be - immobility, screaming, groaning, or using certain pain gesture etc. are elaborately discussed in the study of bodily gestures which differ cross-culturally in societies (HELMAN, 2007).

This verbal or non-verbal pain behavior is standardized in a culture and may be imitated sometimes for seeking attention or to gain sympathy by revealing public pain without any underlying causes. Such conditions may be attributed to being a hypochondriac, malingerer etc. Those with Munchaunsen's syndrome mimic real pain behavior and often undergo surgical procedures or investigations. It may be masks of psychological stateanxiety state, depression or emotional conflict as it occurs in somatization. In such cases the primary symptoms are complains though later they may not be such but rather there can be weakness, breathlessness, sweating or pain in particular areas of the body. These symptoms are common in low-income countries in the West. However, similar cases have 
been seen in higher socio-economic groups of people in different cultures. In Taiwan, people do not display their emotional distress, but it is expressed as the physical or somatic language of pain. Arthur Kleinman studied them and remarked that Chinese cultures define somatic complaints as primary complaints, even if it is physiological. Further he explained records of the OPD of a hospital in Taiwan where about 70 percent of patients visit the OPD for physical symptoms (KLEINMAN 1988). It is also interesting to explore that how one may feel pain or how one describes or expresses it varies from person to person. Often it is described in one's local language and the belief it holds about their own body. I often see in our Neurology OPD, patients present symptoms of headache on different locations in the head and a clinical examination may be different to co-relate with their presentation of symptoms. Seldom patients do not know equivalent language to the medical terms i.e. migraine! Whenever such pain presentations arise then the clinician tries to rule out psycho-somatic pain, then further questions like: does it travel to the left arm from the head? Or does it occur when you climb stairs? Or does it happen like light banding at the chest? Such questions clinicians generally ask the patients to ascertain the real cause of the pain.

\section{Pain Behaviour: its Socio-cultural aspects}

The socio-cultural aspects of pain we can see as the relationship of the body, duration, and its nature determining relationship - how is it expressed to people in society? Pain as a social relationship with society can be examined in three aspects of human growth and development: child rearing practices; pain in birth rituals; pain in religious healing; and pain in rites of passages and pain politics (HELMAN 2007). It is very important to know the expectations of pain behavior. Why do people express certain pain behavior? Is it learned during childhood or in infancy? Child rearing practices normally shape the attitudes of parents' expectations of pain in later life. As Zborowski (1952) found among American parents, cultural values, ethnic background, parent substitutes, peer groups, and siblings all together contribute to child rearing practices. Pain behavior in childbirth also varies for communities or societies. Normally childbirth is a welcome sign of joy and celebration of new arrival to the folk women. Van Hollen (2003) studied childbirth in government hospital in South Indian villages, where women frequently do ask for oxytocin injections to enhance the labour pain. This enhancement of pain is assumed as an indicator of the 
"shakti" of the women who are to deliver the baby soon, in contrast to western hospitals, where women prefer to take analgesic drugs to reduce this pain.

Pain in rituals or religious healing is very common in all cultures and societies. As already discussed about private pain or public pain behavior, cultural rituals are performed for healing bodily pain. In public pain ceremonies, mainly religious, for healing among communities of Africans and Latin Americans and rural areas of western countries such healing pattern are very common as religious rituals for personal and religious transformations. In a Welsh spiritualist church, women are encouraged to share their painful symptoms with others, and to be "possessed" by the pain of an ill member, so it helps in lessening her pain by sharing it among themselves. Similarly, a healer in a Catholic Charismatic Renewal movement in the USA embodies the pain of sufferers which is part of the diagnosis as well as the healing. Furthermore, among some Episcopalians pain is thought of as God-given, so that God becomes closer to such people who feel pain. People of an eastern meditation group think of pain as a message to an individual's body. Those who perform yoga, body ashans in traditional India, express pain as the body language where something has gone wrong within the body and is being messaged to the person.

There are other aspects of ritualistic pain which are self-generated, e.g. self-flagellation or mortifying the flesh are very common among the religious. These symbolize the way to commemorating the spiritual deities. Self-flagellation practices were very common among Christian monastic orders and religious movements. Some Christian communities still practice this. There is Holy Week in the Philippines, when the practice of self-flagellation occurs to remember Jesus Christ, while in some others it is on Good Friday; there is also the ritual of penitence, when some persons nail themselves to a cross to commemorate Christ's own crucifixion; some of these practices are not approved by the Catholic Church. Similarly, self-flagellation practices are common on the occasion of Moharram in some sect of Islam wherein they commemorate the martyrdom of Imam Hussain at the Battle of Karbala. During the tenth day of the public procession of Mohrram, people flay the upper back with a chain containing small knives which leaves several scars on the backs of the people. Similarly, there is the annual Katargama Esla festival in Sri Lanka where Hindu and Buddhist worshippers fire-walk on red hot embers or suspend their bodies from ropes with hooks embedded in their skin. Such self-flagellation in Sri Lanka is done for fulfilling the promises made to their god Sri Skanda. 
Pains in rites de passage, rituals in one's life, are public expressions of pain. These are parts of rituals performed at different ages of a growing person to mark social identities, for example male and female child circumcision or the painful initiation rituals of being warriors. In some of traditional societies there are healing rituals performed by their community healers. Helman (2007) mention their social function in the community; she has explained the relevance of these rituals for acute pain. She mentions two aspects of their function - a biological function for survival and social togetherness. In the case of the former it breaks the barrier between people and enhances the potential for social relationships. In her words, sensory experiences of acute pain are essential for community building. Further she explains Chinese acupuncture, she stresses healing through the needling is the main therapeutic process - where healers and the patients become socially connected, which may be therapeutic in unspecific ways. This process is not well recognized by modern medicine. These examples explained the acute pain and their management and their social function in public life. It is a pathway to the religious rituals may lead to greater self knowledge, absolution or making a new social identity.

There is a politics in pain expressed in public or private life or it may be used as a tool for torture. When it is for political gain, a regime of torture depends upon the public pain exhibiting the power of the State forces. There is the UN Convention against Torture (1995) wherein torture of any kind to a person is prohibited. This Convention curbs it in all manners, but as it has been in the history of mankind it continues. It is practiced openly among people in political power groups, religious sects etc. It can go to any sexual humiliation, social isolation and other kinds of psychological suffering to any person. There are well planned reasons for torture which are often linked to political roles which make them visible (SCARRY 1995).

\section{Chronic Pain (CP): Why should Anthropologists study it?}

Chronic pain (CP) is a private pain disorder and remains invisible to the "other," e.g. family or friends, in how it began and continues causing suffering and distress. Different aspects of chronic pain are discussed well in six articles of neuropsychiatry (CHATURVEDI, JACOB AND SOMASHEKAR 1999). Kleinman et al. (1992) explained that depression, anxiety and other serious conditions often accelerate chronic pain. 
Good, Brodwin and Kleinman (1994) have discussed chronic pain and its anthropological needs for further study. They have enumerated the reasons - the effects of environmental hazards, power structures in the workplace, a crisis in disabilities, and the relations to welfare programmes, negative consequences of medicalization and its relations to the political economic market systems for pain-related products, pain professionals and pain institutions or clinics, therefore adding further economic changes or transformations in political economic potential or further investigation and emotional embodied experiences (CSORDAS 1990). They studied stress as embodiment structures as a cultural category and its relationship with the body, meaning and institution. Some psychological and medical anthropologists expressed the need to examine pain in the local cultural category. Human conditions, a variety of meanings, sources and consequences of human suffering must all be looked together as part of an anthropological study of chronic pain (KLEINMAN 1988; KAUFMAN 1988). These anthropologists are frustrated with "business as usual," which means their examination of chronic pain (CP) and its suffering as the sum of experience of clinicians in the local cultural categories. Most of the medical or psychological anthropologists have written well about chronic pain as a human condition of suffering where one may analyze the cultural aspects, its meaning to friends and family members and to the patients themselves. In this sense study of chronic pain in anthropology explores its source, the variety of meanings and consequences of suffering (GOOD BRODWIN - KLEINMAN 1994). Chronic pain experience and its resistance of suffering lead to biomedical treatment and psychological care. Can chronic pain in the body be mapped? Here its mapping must be recorded because the body is both source as well as site of this pain. This part of chronic pain is very poorly recorded as narratives in any anthropological research study concerning pain.

Can anthropology speak for this pain? Yes, it can. The interpersonal experiences of the person in pain must be recorded and must be placed in the centre of an analysis of chronic pain. This analysis will inscribe all the history of cultural meaning and conflicting social relations which all should be the subject of analysis for anthropology. Well analyzed and recorded experiences of those in pain are required. Anthropology must explore four aspects of chronic pain: first, how can anthropology adequately represent the experiences and situate chronic pain in the main analysis? Second, anthropology must reveal the relationship between chronic pain experiences and narratives as told by patients or sufferers, and infer the nature of pain experiences in the stories told by the narratives those who are in the pain. Kleinman felt that narratives of experiences have turned to the 
humanities for re-interpretations of illness and its narratives (KLEINMAN 1988; MATTINGLY 1989; GOOD 1990). Third, can anthropology reveal the chronic pain embedded in broad ways between body and society? Besides, how can anthropology illuminate phenomenologies of chronic pain experiences? This is the third area where anthropology needs to explore critical phenomenology of chronic pain experiences which a body goes through in the society. In this sense the body generates experiences in response to social realities of the local world and its relationships to a wider society. Hence the studies of $\mathrm{CP}$ require a critical phenomenology for better understanding the resonance in the local social world. Last, medical anthropology must illuminate the experiences of chronic pain in the local world and then its relationship to a wider and complex society. Anthropology has not yet begun this exploration. Precisely chronic pain is an important health problem and its medical treatment remains a costly affair - drugs, surgical procedures, pharmacology and other diagnostics in modern medicine (GOOD BRODWIN - KLEINMAN 1994).

A Biomedical researcher sees pain as a change in "material". This material can be, predominantly, sensory receptors, afferent neural relays and the higher cortical modulating of the pain. This is a reductionist approach to analyzing the prevailing paradigm-molecular or physiological investigations. In this approach the investigations are reduced to the biological approach of malfunctioned organs or tissues. Pain is then correlated to this investigation. Furthermore, tissue pathology, if any is seen, can be attributed to it and considered more valid than electrophysiological pathology. But such investigations into the malfunctioning of the body or pain then neurobiological co-relationship and sociopsychological processes contain large gaps which do not reveal the felt experience of the patients (ibid).

These perspectives from a biomedical or biological approach, reductionism, often have failed to illuminate its continuity and its disability. Chronic illness in this way is a "natural course" which reveals a plan of development where as the "disease" is an element, a natural phenomenon. Similarly, disability is an impairment which results from the "natural course" of this disorder. Further disability has been studied well as an administrative and political category whose meaning and interpretation depend upon the context wherein it is used (GOOD - BRODWIN - KLEINMAN 1994).

Kleinman has studied suffering in the local world of patients in Taiwan and China. He has linked various dimensions- social inequality, oppression, and extraordinary and political 
events which occurred during the Cultural Revolution in China. He compared this in his work "Social Origin of Distress and Diseases: Depression, Neurasthenia and Pain in Modern China (1986)" to different patients and communities in contemporary North America. He mentioned people expressing symptoms of body pain, fatigue, and weakness which are attributed as neurasthenia, a different category in Chinese folk medicine during the Cultural Revolution in China. He concludes his research in his work as: the body mediating mechanism to social and political forces and their interpretations with reference to body structures and functions. He expressed the need to study macro-social processes affecting the human body in cross-cultural ways. The different cross-cultural ways must be analyzed for better understanding the experiences of human body phenomenologies. Further, he expresses the need to explore the construction of "self" in the local world- how it is built up and created in the local world that has shaped it.

He elaborately explained pain as the human experience of suffering, but the nature of its suffering varies. He traces it since World War II and the accounts of the day-to-day events which occurred and caused brutality. Further he observed how the soldiers fought the war, their accounts of suffering- bounded bodies, fear of death etc. Such suffering is also a pain, generated through human actions. Similarly pain in other form have been well reported for the survivors, e.g. systematic murder in Auschwitz, Hairng Ngor (1987) explains experiences of Cambodian genocides; Nein Cheng (1986) write about the Chinese Cultural Revolution, Veena Dass (1989) has written about the Bhopal gas Disaster, where a thousand people fell victim and she writes about the anti-Sikh Riots in 1984, all describing human suffering. Most of them are man-made disasters, systematic discrimination, poverty, etc. and therefore the human suffering is endless, mentions Kleinman (GOOD BRODWIN - KLEINMAN 1994).

\section{Pain Metaphors-Do Nerves speak them?}

Do we express when we are in pain? Yes. We all do. What are these expressions? The language or phrase of pain which most of us express are metaphors that form our lives in this part of northern India or broadly in all South Asian countries. These metaphors of life reflect our social pain through our body as the medium for expressing its own stress. Let's think of another example: social exclusion is experienced as painful because reactions to 
rejection are mediated by aspects of the physical pain system. Here we can think of recent events in our country - how social discrimination leads to inducing social pain (see the university students' suicide among the marginalized population) in our country ${ }^{2}$. It begins to overlap between social and physical pain as an evolutionary development to aid social animals in responding to threats to their inclusion. Research studies suggest that metaphors are culturally embedded in the social fabric reflecting social pain. Such profound distress is experienced when social ties are absent, threatened, damaged, or lost. This involves neural and neuro-chemical substrates in processing physical pain (EISENBERGER 2012; EISENBERGER - MACDONALD - LEARY 2005; PANKSEPP et al 1980). In other words, social separation or disconnection or exclusion hurts in a real way because it activates the neural mechanisms that respond to physical injury. This separation may be seen as the absence of social relationships in either the family or kinship. In addition, it is emphasized in the marriage, kinship and family network; if these do not work well or malfunction, then social disconnection or separation finally generate social pain. Anthropology here can provide us with deep insights into the local world of suffering generating pain. We may infer from these studies that social pain generates physical pain through a dialectical relationship. Therefore, it is pertinent to understand social pain, its generation mechanism and maintenance leading to physical pain ${ }^{3}$.

\section{Social and Physical Pain overlap: Neuro-chemical Evidence}

Anthropologists are well aware of the evolutionary pain mechanism and may agree that solitary individuals were ill-equipped to face the daunting challenges of their environment.

2 Social exclusion and social inclusion is a category culturally constructed and officially recognized In term of exclusion social pain, we can think of recent events e.g. in south India forced famous suicide of Rohit Vemeulla, a dalit research scholar in Central University of Hyderabad, murder of Gauri Lankesh, an eminent journalist and intellectual writer; Cow meat eaters, Muslims, in north India etc. Here just think how social discrimination lead to social pain!

3 Here I wish to mention about a Pain Management Clinic (PMC) in our OPD. I recall that once Department of Neuro-anesthesiology proposed this clinic in the Institute. It was initially suggested that it may have different professionals from Neurosurgery, Neurology, Psychiatry, Clinica Psychology, Medical anthropology and Psychiatric social work. This clinic sees pain beyond body in a holistic way and suggests appropriate measures from clinic to home. Now it works in afternoon OPD twice a week in the Institute. 
Therefore, the survival of our ancestors might have depended on the integrity of their social and physical network. Pain may act as a signal to limit damage to the body, making others, human and animal alike, of the possibility of damage to one's social relationships (EISENBERGER -LIEBERMAN 2004; MACDONALD - LEARY 2005; PANSKEPP et al 1980). Physical pain protects animals by caring for the site of the physical injury. It also motivates them to restorative action in their social network, for animals and human beings who enjoy social belongingness in their specific groups (JAREMKA - GABRIEL - CARVALLO 2011). In human evolutionary history we always try to maintain stable and meaningful social relationships with others. It is well evident in human history that our forefathers might always have lived in groups for a better survival mechanism which might have facilitated hunting, foraging, and mating as well as childrearing and provided care during illness, injury and the utter dependency of childhood (BAUMEISTER - LEARY 1995, BOWLBY 1969/1982).

The morphine present in poppies and its injection can control pain immediately (BULGAKOV 1975). These opioid drugs are potent painkillers and also cure social pain or the ache of social loss. Precisely these opioid drugs modulate both physical pain and the social affect. Morphine is a pain-relieving drug which attenuates social separation distress in different animals (CARDEN - HOFER 1990; HERMAN - PANKSEPP 1978; KEHOE - BLASS 1986). However, morphine, if taken in low and non-sedative doses, does not affect normal behavioral responses. In contrast, opioid receptor antagonists are known to aggravate physical pain, increase distress vocalizations in isolated animals (CARDEN - HOFER 1990; HERMAN - PANKSEPP 1978; KEHOE - BLASS 1986) and slow the reduction in distress vocalizations typically seen when animals are reunited with their companions (CARDEN HOFER 1990; HERMAN - PANKSEPP 1978; PANSKEPP et al. 1980). These studies indicate that the endogenous opioid system is a primary neuro-chemical system for regulating physical pain, and mediating social attachments (PANSKEPP et al. 1980).

\section{Neural Evidences: Neural Substrates of Physical Pain}

The experience of physical pain can be divided into two constituent components: the sensory-discriminative and the affective-motivational (TREEDE et al. 1999). The sensory component provides information about the intensity, quality, and spatiotemporal characteristics of the pain stimulus, whereas the affective component is associated with 
the perceived unpleasantness of the stimulus, promotes focus on the pain stimulus, and provides the motivation to terminate the painful experience (RAINVILLE et al. 1999; TREEDE et al. 1999).

These two pain elements are sub-served by different neural mechanisms (TÖLLE et al. 1999; TREEDE et al. 1999). Pain sensation is processed in the primary and secondary somatosensory cortices (SI and $\mathrm{SII}$ ) and the posterior insula (PI), whereas pain affect relies on the dorsal anterior cingulate cortex (dACC) and the anterior insula (AI) (Figure-1). Although highly correlated, the dissociability of the two components of pain is evident in the fact that individuals with lesions to the dACC and the AI (BERTHIER - STARKSTEIN LEIGUARDA 1988) can still identify the presence of pain, but find it less bothersome and distracting. Given that social exclusion does not involve tissue damage but does require an efficient mechanism for capturing attention and motivating pain-terminating behavior, it is probable that the affective component of physical pain is more directly involved in social pain experience, although the sensory component has been shown to play a role in certain types of social pain as well (KROSS et al. 2011).
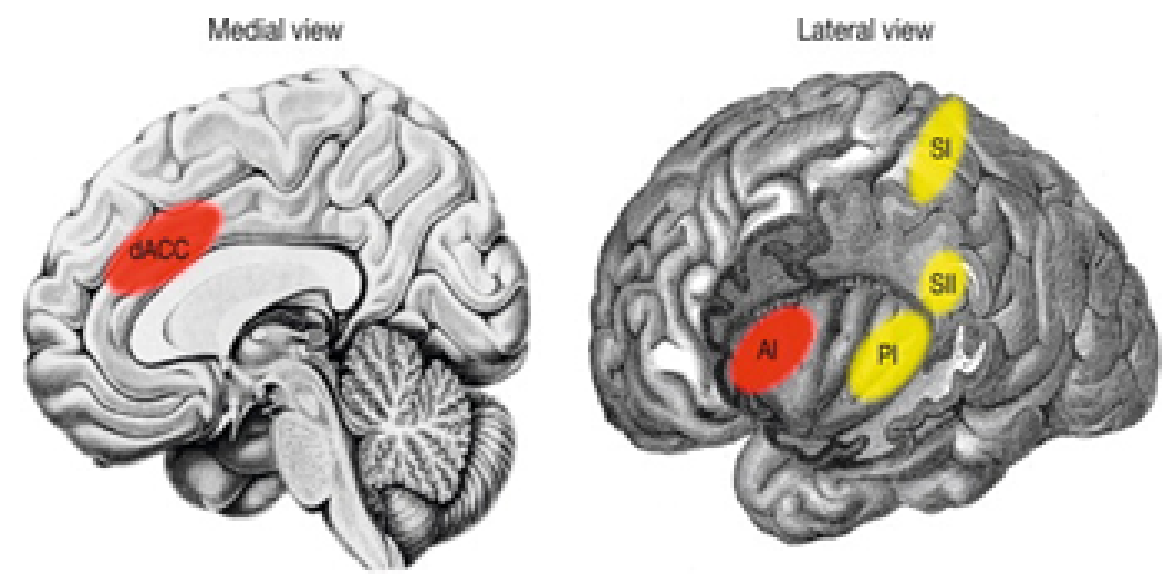

Figure 1: Cortical substrates of the affective and sensory components of pain. Regions displayed in red are hypothesized to be more strongly involved in the affective component of pain while regions displayed in yellow are hypothesized to be more strongly involved in the sensory component of pain. The medial view (on the left) shows the dorsal anterior cingulate cortex ( $A A C C$ ). The lateral view (on the right) shows the anterior insula (Al), posterior insula (PI), primary somatosensory cortex (SI), and secondary somatosensory cortex (SII). 
The social and physical pain overlap reveal neural evidences related to various anatomical parts of brain. This dialectical relationship remains under the influences of external circumstances, and the social situation causing physical pain

\section{Conclusion}

I have reviewed in this paper pain as the suffering of the body and mind from an anthropological perspective, which mainly concerns the social and physical aspects, neural overlap, neural substrate, misfortune, and metaphors of pain. A multidisciplinary team of professionals were concerned with minimizing pain either in the body or the mind in a neuropsychiatric hospital. Besides other team professionals like epidemiologists and medical anthropologists also focus on the socio-cultural aspects of neuropsychiatric diseases by designing and planning preventive measures for such diseases. The ethnographic work in medical anthropology illuminates humans suffering social pain in everyday life and informs different aspects of pain embedded in our social fabric (LADERMAN 1991, DESJARLAIS 1992, ROSEMAN 1991, CSORDAS 1994, SEREMETAKIS 1991, SCHEPER-HUHGES 1992). Additionally, political and economic power modulate and shape the local world of suffering where bodies remain in social pain mediated to physical pain, which is a big challenge to modern medicine. Medical anthropology can contribute in understanding pain as a reality through its methods-clinical ethnography- in wards, preand postoperative surgeries of the patients and in society. It can open up new avenues of generating knowledge about neuropsychiatric diseases in a holistic manner for research, teaching and training young professionals for healing beyond medicine.

\section{Acknowledgements}

I am thankful to prof. Radoslav Hlusek, editor, Ethnologia Actualis for his quick response and for the comments of anonymous reviewers.

Declaration: Author does not have any conflicting interest. 


\section{Bibliography}

BAUMEISTER, R.F. - LEARY, M.R. (1995): The Need to Belong. Desire for Interpersonal Attachments as a Fundamental Human Motivation. In: Psychological Bulletin, Vol. 117, No. 3, 497-529.

BERTHIER, M. - STARKSTEIN, S. - LEIGUARDA, R. (1988): Asymbolia for Pain: a sensory-limbic disconnection syndrome. Ann Neurol 24: 41-49.

BOWLBY, J. (1969/1982): Attachment and Loss. Vol. I, attachment (2nd ed.) Ed. New York.

BULGAKOV, M.A. (1975): Country Doctor's Notebook, London: Harvill Press.

CARDEN, S.E. - HOFER, M.A. (1990): Independence of Benzodiazepine and Opiate Action in the Suppression of Isolation Distress in Rat Pups. In: Behavioral Neuroscience, 104, 160-166. http://dx.doi.org/10.1037/0735-7044.104.1.160.

CHATURVEDI, S. K. - JACOB, A. - SOMASHEKAR, B. S. (1999). Theme: Chronic pain in Neuropsychiatry. In: NIHMANS Journal 17(3), pp. 193-215.

CSORDAS, T. (1990): Embodiment as a paradigm in Anthropology. In: Ethos 18(1):547.

CSORDAS, T. (1994). The Sacred Self: A Cultural Phenomenology of Charismatics Healing, Berkeley: University of California Press.

DASS, VEENA (1989). What is health? Paper presented at "Health Transition Seminar" Centre for Population Studies, Harvard University, May 1989.

DESJARLAIS, R. (1992): Body and Emotions, Philadelphia: University of Pennsylvania.

EISENBERGER, N.I. (2012): The Pain of Social Disconnection: Examining the Shared Neural Underpinnings of Physical and Social Pain. In: Nature Reviews Neuroscience 13, 421-434, doi: 10.1038/nrn3231.

EISENBERGER, N. I. - LIEBERMAN, M. D. (2004): Why It Hurts to Be Left Out: The Neurocognitive overlap between Physical and Social pain. Source: www.scn.ucla.edu/pdf/Sydney(2004), accessed on 02.011.2016 .

FABREGA, H. - TYMA, S. (1976): Culture, Language and Shaping of Illness. An Illustration of Pain. In: Journal of psychosomatic Reaserch 20:323-337.

GOOD, B. J. (1990): Medicine, Rationality and Experiences: An Anthropological Perspective. Lewis Henry Lectures, New York: University of Rochester. 
GOOD, B. J. - BRODWIN, P. E. - KLEINMAN, A. (1994): Pain as Human experiences: An Anthropological Perspective. Berkeley: University of California Press.

HELMAN, C. G. (2007): Culture, Health and IIlness, London: Hodder Arnold.

HERMAN, B. H. - PANKSEPP, J. (1978): Effects of Morphine and Naloxone on Separation Distress and Approach Attachment: Evidence for Opiate Mediation of Social Affect. In: Pharmac. Biochem. Behav. 9: 213-220, 1978.

International Psychoanalytical Association World Congress, July, 31, 2013. Inaugural Address

JAREMKA, L. M. - GABRIEL, S. - CARVALLO, M. (2011): What Make Us to Feel the Best and Also Makes Us Feel the Worst: The Emotional Impact of Independent and Interdependent Experiences. In: Self and Identity, 10:44-63.

KUUFFMAN, S. R. (1988): Towards a Phenomenonlogy of Boundaries of Medicines: Chronic IIIness Experiences in the Case of Storke. In: Medical Anthropology Quarterly 2: 338-354.

KEHOE, P. - BLASS, E. M. (1986): Behaviourally functional Opioid system in infant rats: I. Evidences for olfactory and gustatory classical conditioning. In: Bahv. Nerro Sci. $100,359-367$.

KLEINMAN, A. (1992): Pain and resistance: delegitimation and redelegitimation of local worlds. In: Pain as Human experiences: An anthropological Perspective. Ed. GOOD, B. J. - BRODWIN, P. E. - KLEINMAN, A. Berkeley: University of California Press.

KLEINMAN, A. (1988): The Illness Narratives: Sufferings, healing and human conditions, Basic Books: New York.

KLEINMAN, A. (1986): Social Origin of Distress and Diseases: Depression, Neurasthenia and Pain in Modern China. New Haven, Conn. YUP.

KROSS, E. - BERMAN, M. G. - MISCHEL, W. - SMITH, E. E. - WAGER, T. D. (2011): Social Rejection Shares Somatosensory Representations with Physical Pain. In: Proc Natl Acad Sci U S A. 2011 Apr 12; 108 (15):6270-5. doi: 10.1073/pnas.110269310.

LADERMAN, C. (1991): Taming the Winds of Desire: psychology, Medicine, and Aesthetics in Malay Shamanistic Performance, Berkeley: University of California Press.

MATTINGLY, CH. (1989): Thinking with Stories: Thinking and Experiences in Clinical Practices. PhD Thesis, MIT, USA. 
MACDONALD, G. - LEARY, M. (2005): Why Does Social Exclusion Hurt? The Relationship Between Social and Physical Pain. In: Psychological Bulletin 131(2):20223 - DOI: 10.1037/0033-2909.131.2.202 · Source: PubMed.

NEIN, CH. (1986): Life and Death in Shanghai, New York: Grove Press.

NGOR, H. (1987): A Cambodian Odyssey. New York: McMillan.

PANKSEPP, J. B. - HERMAN, J. T. - VILBERG, P. B. - DEESKINAZI, F. G. (1980): Endogenous Opioids and Social Behavior. In: Neuroscience \& Biobehavioral Reviews, Vol. 4, pp. 473-487.

PUGH, J. F. (1991). The semantics of pain in Indian Culture and medicine. Culture, Medicine, and Psychiatry, 15, 19-43.

RAINVILLE, P. - HOFBAUER, R. K. - PAUS, T. - DUNCAN, G. H. - BUSHNELL, M. C. - PRICE, D. D. (1999): Cerebral Mechanisms of Hypnotic Induction and Suggestion. In: Journal of Cognitive Neuroscience, 11(1), 110-125.

ROSEMAN, M. (1991): Healing Sounds from Malaynisain Rainforest: Temiar Music and Medicine, Berkeley: University of California Press.

SCARRY, E. (1985): The Body in Pain: The Making and Unmaking of World, New York: Oxford University Press.

SCHEPER-HUGHES, N. (1992). Death without Weeping: The Violence in Everyday Life in Brazil, Berkeley: University of California Press.

SEREMETAKIS, N. (1991). The Last Word: Women, Death and Divination in Inner Mani, Chicago: University of Chicago Press.

TÖLLE, R. T. - KAUFMANN, T. - SIESSMEIER, T. et al. (1999): Region-Specific Encoding of Sensory and Affective Components of Pain in the Human Brain: A Positron Emission Tomography Correlation Analysis. In: Ann Neurol 45:40-47.

TREEDE, R. D. - KENSHALO, D. R. - GRACELY, R. H. - JONES, A. K. (1999): The Cortical Representation of Pain. In: Pain 79, 105-11110.1016/S0304-3959(98)001845 .

VAN HOLLEN, C. (2003): Invoking vali: Painful technologies of modern birth in South India. In: Medical Anthropology Quaterly 17 (1) 49-77.

ZOBOROWSKI, M. (1969): People in Pain. San Francisco: Jossey Bass.

ZOLA, I. K. (1996). Culture and Symptoms: an analysis of patients' presenting complaints. In: American Sociological Review 31, 615-30. 